\title{
On the use of landscape surrogates as ecological indicators in fragmented forests
}

\author{
D.B. Lindenmayer ${ }^{\mathrm{a}, *}$, R.B. Cunningham ${ }^{\mathrm{b}}$, C.F. Donnelly ${ }^{\mathrm{b}}$, R. Lesslie \\ ${ }^{\mathrm{a}}$ Centre for Resource and Environmental Studies and Department of Geography, \\ The Australian National University, Canberra, ACT 0200, Australia \\ ${ }^{\mathrm{b}}$ Statistical Consulting Unit of the Graduate School, The Australian National University, Canberra, ACT 0200, Australia \\ ${ }^{\mathrm{c}}$ Department of Geography, The Australian National University, Canberra, ACT 0200, Australia
}

Received 14 August 2000; accepted 27 December 2000

\begin{abstract}
Given the potentially negative effects of forest fragmentation on biodiversity, governments and management agencies have sought generic landscape measures of forest fragmentation to monitor changes in forest cover-measures that also may be informative for decisions relating to changes in biodiversity. In this paper, we discuss issues relating to the evaluation of landscape surrogate measures and their usefulness as ecological indicators. We illustrate some of these points by a detailed examination of statistical relationships among several target responses (defined as the occurrence of particular species), and a selection of landscape surrogate measures in two forest regions of southeastern Australia.

There was no evidence in our data that surrogate landscape measures have generic applicability for the conservation of large sets of species. Although landscape surrogates may be useful where the aim is to quantify current landscape patterns from a human perspective or to monitor the extent and rate of change in that pattern over time, they may not have biological and statistical significance for particular elements of the biota. There is a need for a clear definition of units and measures, a need to be aware of redundancy among potential surrogates, and a need for the establishment of a framework for rigorously evaluating ecological indicators. (C) 2002 Elsevier Science B.V. All rights reserved.
\end{abstract}

Keywords: Landscape measures; Surrogates; Ecological indicators; Forest fragmentation; Arboreal marsupials; Forest birds; Fence effects; Human disturbance; Southeastern Australia

\section{Introduction}

Habitat loss and fragmentation are widely regarded as major factors contributing to the loss of biodiversity (Groombridge, 1992). For example, more than $80 \%$ of the world's endangered birds are threatened by habitat loss (Temple, 1986). The loss of biodiversity is a

\footnotetext{
* Corresponding author. Tel.: +61-25-0654; fax: +61-2-6125-0757.

E-mail address: davidl@cres.anu.edu.au (D.B. Lindenmayer).
}

particularly significant problem in forests because forests are some of the most species-rich environments on the planet; not only for vertebrates such as birds (Gill, 1995), but also invertebrates (Majer et al., 1994), and microbes (Torsvik et al., 1990). Biodiversity loss in forests can occur as a direct result of vegetation clearing (Laurance and Bierregaard, 1997), and also because of management activities in the production of timber, pulp and other commodities (e.g. Virkkala et al., 1994), which can fragment populations of forest-dependent organisms (Lamberson et al., 1994; Økland, 1996). 
In an attempt to manage forests in an ecologically sustainable way by ensuring the maintenance of forest biodiversity, governments and forest management agencies have sought to develop sets of criteria and indicators of sustainability. The level of activity and interest in this area is unprecedented and numerous organisations are developing criteria and indicators for sustainable forest management. Arborvitae (1995) listed more than 10 organisations developing forest sustainability criteria around the world (e.g. Convention for Sustainable Development Intergovernmental Panel on Forests, United Nations Food and Agriculture Organisation, Helsinki Process, Montreal Process, International Standards Organisation, International Tropical Timber Organisation, Amazon Process Guidelines and World Commission on Forests and Sustainable Development).

The Montreal Process, and its associated set of criteria and indicators of sustainability, has been adopted for Australian forests (Commonwealth of Australia, 1998; Canadian Forest Service, 2000). The development of landscape measures of fragmentation is one of the key criterion of the Montreal Process (Criterion 1.1e) for guiding the conservation of biodiversity in managed forests-a legacy of concerns about the potentially negative effects of forest fragmentation on biota. Measures to characterise the spatial structure of forest landscapes typically include three types of components (Wegner, 1994). These are as follows:

- Composition or the identity and characteristics of the different types of patches in a landscape.

- Configuration which is the spatial arrangement of the patches or units in a landscape.

- Connectivity which describes the ease with which organisms move along particular landscape elements (such as wildlife corridors).

Using these components as a basis, a large number of landscape measures have been developed in the past decade (reviewed by Haines-Young and Chopping (1996)). Cale and Hobbs (1994) note that these measures have been calculated at both a regional scale where measures of landscape pattern are compared between landscapes, and at a landscape scale in which within landscape differences are examined. The vast majority of landscape measures for changes such as habitat fragmentation have yet to be shown to be useful (Noss, 1999).

Although there are many criteria and concepts proposed in the literature which relate to the spatial structure of forest landscapes, there is a noticeable lack of definition of the quantities to be used and how these quantities will be measured. Thus, in the search for measures to monitor landscape fragmentation as part of ecologically sustainable forest management, there is a clear need for a definition of appropriate measures and a need to establish a scientific framework for evaluating them. Some of the key issues to be addressed include:

- A clear definition of the target response and how it is to be measured. For example, if the focus is on "biodiversity", it should be clearly stated how this is to be measured, how data are to be gathered, and what the measured values mean.

- A clear definition of the forest management units to which landscape measures will be applied, and for which inferences are to be made. For example, is it a site of prescribed dimensions, a patch of remnant vegetation, a landscape (with dimensions to be defined), or a region? Implicit in the above list is a natural hierarchy of units or scales. Clear definition will assist the collection of data at an appropriate scale and so reduce the chances of gathering observations at an inappropriate scale. In addition, the scale of measurement also must be relevant to the target response.

- A statement of the objectives in terms of decisionmaking. This will involve inferences about parameters of the target response for the declared units or some aggregation of them. (For example, a comparison of a target response among remnants within several landscapes, or a test of a hypothesis that landscape disturbance has no effect on a target response.)

- In many circumstances it may not be possible to measure the target directly and so it may be necessary to seek indirect or surrogate measures that may provide a basis for inferences about the direct measure. This is what we understand to be meant by an ecological indicator- "indicators are not intended to assess directly sustainability at the management unit level" (Commonwealth of Australia, 1998). 
- The establishment of a scientific framework for evaluating surrogates for making inferences about the target response. For example, is a strong correlation between the surrogate and the target response a critical factor in determining the validity of the surrogate for the desired inferences? Can we make inference about a question framed in terms of a target response using surrogates or ecological indicators?

Before discussing these issues further, we present the results of two case studies of the relationships between several target responses and several landscape surrogates. These analyses help focus on some of the key issues raised above.

\section{Relationships between target responses and landscape surrogates: two case studies from Australian forests}

Empirical relationships between the occurrence of some selected bird and arboreal marsupial taxa (as target response measures of "biodiversity"), and landscape surrogates were explored. Data were obtained from montane ash forests of the Central Highlands of Victoria and the Tumut region of southern New South Wales.

\subsection{Study areas}

A continuous cover of native Eucalyptus forestprimarily montane ash forest (Commonwealth of Australia and Department of Natural Resources and Environment, 1997) dominates the Central Highlands of Victoria. Montane ash forests are comprised of a mosaic of forest age classes; young (1-30 years old) logged and regenerated regrowth stands, post-fire regrowth stands (17-180 years old), and stands unburned for more than 350 years (Lindenmayer et al., 1999a). Long-term studies of the distribution and abundance of arboreal marsupials have been completed in montane ash forests (Lindenmayer et al., 1991a, 1994). The presence and abundance of eight species of arboreal marsupials have been estimated on a repeated basis at more than 250 sites, each 3 ha in size, and dispersed widely throughout the region. These sites vary in stand age, human disturbance history (e.g. logging history and fire history), and a range of environmental attributes (Lindenmayer et al., 1999a). Further details of the species sampled and the protocols employed in field studies are presented in Lindenmayer et al. (1991a, 1994).

The second case study area at Tumut is an extensive (50 000 ha) exotic softwood Radiata Pine (Pinus radiata) plantation (Lindenmayer et al., 1999b). The plantation contains 192 patches of remnant eucalypt forest of varying sizes, shapes and forest types that are the remains of the original native forest cover that was cleared to establish the Radiata Pine plantation. The landscape context (sensu Enoksson et al., 1995) of the eucalypt remnants also varies; some are surrounded by stands of uniform-aged Radiata Pine and are remote from other eucalypt remnants, whereas others are close to neighbouring remnants and only 200-300 m of softwood forest separates them. Data on birds, terrestrial mammals, and arboreal marsupials gathered at Tumut are reported elsewhere (Lindenmayer et al., 1999b,c, 2001).

\section{Case study 1 -Central Highlands of Victoria}

\subsection{Landscape surrogates}

The National Wilderness Inventory is an Australiawide database consisting of a set of computergenerated surfaces that represent the extent of human disturbance across landscapes (Lesslie and Maslen, 1995). These surfaces are derived from a number of primary variables on human settlement, infrastructure, and land use. The geo-coded locations of 151 of our field survey sites in the Central Highlands of Victoria were overlaid on these data surfaces, at a grid resolution of $500 \mathrm{~m}$. Measures of wilderness quality (or the degree of exposure to human activity) in the neighbourhood of each chosen site were the following:

1. Remoteness from settlement (RS) - a measure of remoteness from permanent habitation.

2. Remoteness from access (RA) - a measure of remoteness from constructed or established access routes and roads.

3. Apparent naturalness $(\mathrm{AN})-\mathrm{a}$ measure of the degree to which the landscape is free from permanent human structures. 
4. Biophysical naturalness $(\mathrm{BN})-\mathrm{a}$ measure of the degree to which the landscape is free from biophysical disturbance caused by modern land use activities.

5. Total wilderness quality (TWQ) - a measure derived by summing standardised values of the four previous measures.

Further details on the derivation of these variables are provided in Lesslie and Maslen (1995).

Preliminary exploration of these landscape surrogates revealed very high collinearity (and hence redundancy) between them. Principal components analysis (Digby and Kempton, 1987) was used to identify the underlying variables and to reduce the dimensionality of the problem. Two components relating to proximity to access were identifiedinfrastructure and settlement features (RA, RS and $\mathrm{AN})$, on the one hand, and the intensity of land use $(\mathrm{BN})$ on the other. Statistical modelling (McCullagh and Nelder, 1989) was used to explore relationships between the presence of various species of arboreal marsupials (i.e. the target responses), and the two principal component scores (i.e. the landscape surrogates).

\subsection{Target responses}

Data on the presence and abundance of arboreal marsupials at 151.3 ha sites in the Central Highlands of Victoria (see Lindenmayer et al., 1991a, 1999a) were chosen for studying relationships with surrogate landscape measures. The defined "unit" for the case study was a site of 3 ha in size. The target response variables selected were the presence/ absence of Leadbeater's Possum (Gymnobelidues leadbeateri), Greater Glider (Petauroides volans) and Mountain Brushtail Possum (Trichosurus caninus) as well as the total abundance of arboreal marsupials per se (i.e. the sum of all species combined).

\subsection{Relationships}

No significant relationships were obtained between any of the target response variables (i.e. the various species of arboreal marsupials) and the derived surrogate measures.

\section{Case study 2-Tumut}

For this case study, data analysis focussed on 86 eucalypt remnants that varied in size from 1 to 124 ha. A 3 ha site within these eucalypt remnants was the "unit" of analysis.

\subsection{Landscape surrogates}

For each remnant, "landscape areas" were defined by concentric circles of radius 200,400 , and $2000 \mathrm{~m}$ around the centroid of each of the 86 eucalypt remnants. Data relating to several landscape measures (see below) were derived using a Geographic Information System (GIS). Surrogate measures were chosen on the basis of their relative computational and intuitive simplicity, and they were as follows:

1. amount of (eucalypt forest) habitat in a landscape;

2. spatial sub-division of habitat in a landscape;

3. patch isolation;

4. patch shape and edge (or core) area;

5. relative density of roads in the landscape area surrounding each of the 86 eucalypt remnants.

The measures are summarised in Table 1.

The size and shape of many eucalypt remnants meant that the 200 and $400 \mathrm{~m}$ polygons frequently encompassed only the remnant itself and so were not large enough to capture information on the characteristics of the landscape surrounding it. Hence, detailed statistical analysis was restricted to data from the $2000 \mathrm{~m}$ polygon.

Given the compositional nature of the variables, collinearity among the variables was not unexpected. To meet linearity and distributional assumptions, all variables were transformed by natural logarithms prior to statistical analysis. Dimension reduction by principal component analysis enabled us to identify a set of vectors or scores. The first score was a contrast between remnant size and the mean area of native eucalypt forest within the $2000 \mathrm{~m}$ polygon versus the number of eucalypt remnants and the mean minimum distance to other areas of native vegetation within the $2000 \mathrm{~m}$ polygon. Hence, the contrast essentially reflected whether the eucalypt vegetation was consolidated (a negative score) or patchy (a positive score). 
Table 1

Landscape variables used as potential surrogates in the Tumut case study

\begin{tabular}{|c|c|}
\hline $\begin{array}{l}\text { Code for landscape } \\
\text { measure }\end{array}$ & Description \\
\hline REMNANT AREA & The precise size (to the nearest $0.1 \mathrm{ha}$ ) of a given eucalypt remnant within which the survey site was located \\
\hline AREA & $\begin{array}{l}\text { The total area of native vegetation cover }\left(\mathrm{m}^{2}\right) \text { within the "landscape area" targeted for study (i.e. the circle of radius } \\
200,400 \text { and } 2000 \mathrm{~m} \text { around the site centroid) }\end{array}$ \\
\hline NP & Number of native eucalypt patches within the study polygon \\
\hline MPS & Mean area of native vegetation patches within the study polygon; a measure of spatial sub-division \\
\hline MPSSTD & Standard deviation of MPS values within the study polygon; a measure of variability in patch size \\
\hline LPI & $\begin{array}{l}\text { Largest patch index which was the proportion }(\%) \text { of the study polygon covered by the largest patch of native } \\
\text { vegetation; a measure of spatial sub-division }\end{array}$ \\
\hline TCA & $\begin{array}{l}\text { Total core area which was the sum of the area of "core" native vegetation; the "core" area is the area of a given patch } \\
\text { that is at least two cell widths }(40 \mathrm{~m}) \text { from the patch edge; an integrated measure of patch edge and shape }\end{array}$ \\
\hline NMEAN & $\begin{array}{l}\text { Mean minimum distance }(\mathrm{m}) \text { to native vegetation (up to a maximum of } 200 \mathrm{~m} \text { ) of all cells within the study polygon; a } \\
\text { measure of isolation }\end{array}$ \\
\hline RDEN & Density of roads within the study polygon measured as the sum of all cells within the study polygon bisected by a road \\
\hline
\end{tabular}

\subsection{Target responses}

The following target response variables were used for exploring relationships with various landscape surrogates:

- The total number of arboreal marsupials recorded.

- The presence/absence of the Greater Glider and the Common Ringtail Possum (Pseudochierus peregrinus).

- Detection rates for the following bird species: Crimson Rosella (Platycercus elegans), Grey Fantail (Rhipidura fuliginosa), Red Wattlebird (Anthochaera carunculata), Eastern Yellow Robin (Eopsaltria australis), Golden Whistler (Pachycephala pectoralis), and Rufous Whistler (Pachycephala rufiventris). Point interval counts of birds were made a stations set at $100 \mathrm{~m}$ intervals along a permanently marked $600 \mathrm{~m}$ long transect. The detection rate was the proportion of the (seven) plots along the $600 \mathrm{~m}$ long transect established at a given site where at least one bird of particular species was recorded (see Lindenmayer et al. (2001) for further details).

\subsection{Relationships}

In contrast to the study in the Central Highlands of Victoria, regression analysis showed significant $(P<$ $0.05)$ relationships between the occurrence of most species examined and landscape variables. Responses for arboreal marsupials are summarised in Table 2 and effects are shown graphically in Fig. 1. There was evidence $(P=0.02)$ that the probability of detecting a Greater Glider in a patch increased as the log of remnant area increased in the surrounding landscape (Fig. 1a). The total number of arboreal marsupials increased significantly $(P<0.001)$ with increasing $\log ($ remnant area) (Fig. 1b), but it decreased significantly $(P=0.02)$ with $\log ($ area of native vegetation cover) (Fig. 1c). Similarly, for the Common Ringtail Possum, the probability of occurrence of

Table 2

Parameter estimates and standard errors for relationships between the abundance or probability of occurrence of arboreal marsupials and landscape measures at Tumut

\begin{tabular}{lll}
\hline Variable & Estimate & S.E. \\
\hline
\end{tabular}

(A) Probability of occurrence of the Greater Glider (effects shown graphically in Fig. 1a)

$\begin{array}{lrr}\text { Constant } & -2.595 & 0.665 \\ \log (\text { remnant area }) & 0.494 & 0.229\end{array}$

(B) Total number of arboreal marsupials (effects shown graphically in Fig. 1b and c)

$\begin{array}{lrr}\text { Constant } & 4.720 & 2.320\end{array}$

$\log$ (area of native vegetation cover) $\quad-0.353 \quad 0.168$

$\begin{array}{lll}\log (\text { remnant area }) & 0.389 & 0.093\end{array}$

(C) Probability of occurrence of the Common Ringtail Possum (effects shown graphically in Fig. 1d and e)

\begin{tabular}{lcl} 
Constant & 2.94 & 2.84 \\
$\log ($ mean area of patches $)$ & 0.809 & 0.347 \\
$\log ($ remnant area $)$ & -0.939 & 0.414 \\
\hline
\end{tabular}



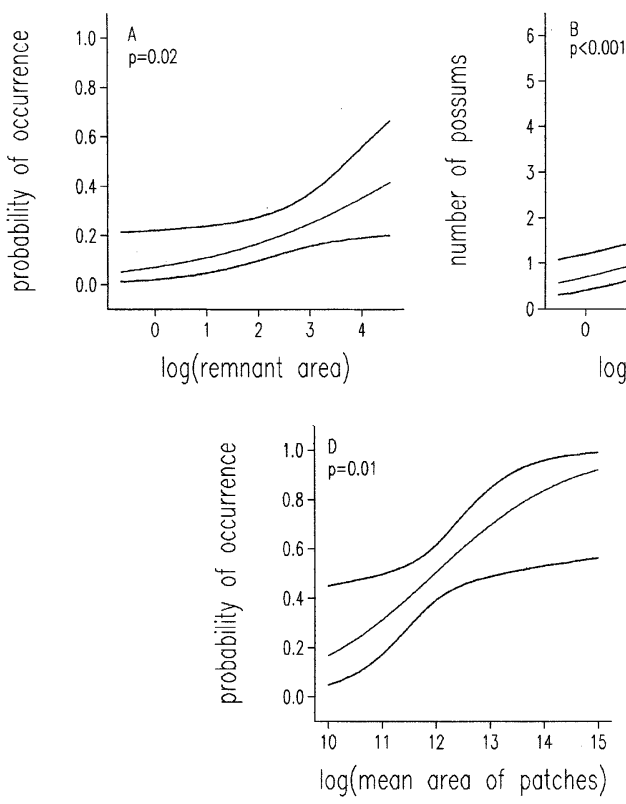
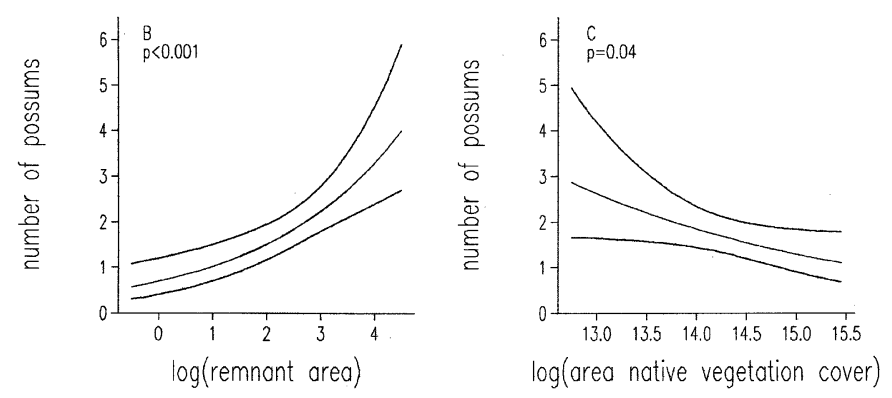

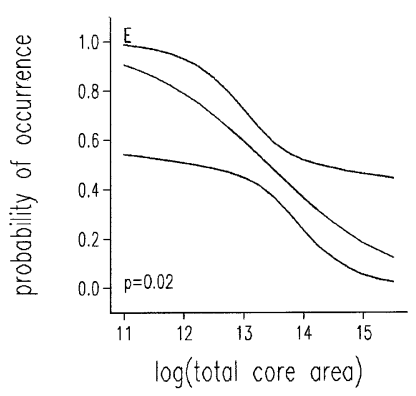

Fig. 1. Graphical representation of relationships between the probability of occurrence of the Greater Glider (A), the abundance of arboreal marsupials (B and C), the probability of occurrence of the Common Ringtail Possum (D and E) and significant landscape variables.

the species increased significantly $(P=0.01)$ with the $\log ($ mean number of remnants) (Fig. 1d), but decreased significantly $(P=0.02)$ with $\log ($ total core area) (Fig. 1e).

Regression analysis showed significant relationships between the detection frequency of birds and landscape variables (Table 3, Fig. 2). Parameter estimates for the statistical models for each bird species examined are given in Table 3 and effects are shown graphically in Fig. 2. Each relationship contained a different set of significant explanatory variables (Table 3), even for the two species from the same genus (the Rufous Whistler and Golden Whistler). In other cases, a surrogate measure was significant in models for two species, but the nature of the response was different. For example, there was a positive relationship between the probability of detection of the Grey Fantail and mean minimum distance to native vegetation, but a negative one for the Golden Whistler (Table 3, Fig. 2). For the Crimson Rosella, the probability of detection increased significantly $(P=0.003)$ with $\log$ (total core area), but decreased significantly $(P<0.001)$ with $\log ($ mean area of remnants) and $\log$ (area of native vegetation) $(P=0.004)$ (Table 3, Fig. 2).
Significant relationships were found between the probability of detection of several species of birds and the patchiness score derived by principal components analysis (Table 4, Fig. 3). Significant effects included those for the Crimson Rosella $(P<0.001)$, Grey Fantail $(P=0.04)$, and Red Wattlebird $(P=0.04)$. No effects were identified for the Eastern Yellow Robin. There was weak evidence $(P=0.06$ and $P=0.07$, respectively) of an effect for the Rufous Whistler and the Golden Whistler. The signs for the effects varied between species, indicating they responded differently to the landscape mosaic at Tumut. The probability of detection of the Red Wattlebird and Golden Whistler was greater if remnant eucalypt cover was consolidated, whereas for the Crimson Rosella, Grey Fantail and Rufous Whistler, it was greater if remnant eucalypt cover was patchy and dispersed among many remnants.

\section{Discussion}

\subsection{The need for a rational framework for evaluating ecological indicators}

In many landscapes, direct measures or values for the target response will be absent and so surrogate 
Table 3

Parameter estimates and standard errors for relationships between the detection frequency of various species of birds and statistically significant derived landscape measures at Tumut ${ }^{\mathrm{a}}$

\begin{tabular}{lcl}
\hline Variable & Estimate & S.E. \\
\hline (A) Probability of detection of the Crimson Rosella (effects shown \\
graphically in Fig. 2a-c) & 13.89 & 3.56 \\
Constant & 0 & - \\
Year 1997 & -0.572 & 0.196 \\
Year 1996 & -0.572 & 0.525 \\
$\log ($ area of native vegetation) & -0.501 & 0.140 \\
$\log ($ mean area of patches) & 1.035 & 0.349 \\
$\log ($ total core area) &
\end{tabular}

(B) Probability of detection of the Grey Fantail (effects shown graphically in Fig. 2d)

$\begin{array}{lcl}\text { Constant } & 0.372 & 0.455 \\ \text { Year } 1997 & 0 & - \\ \text { Year } 1996 & -0.680 & 0.227 \\ \text { Mean minimum distance to native } & 0.008 & 0.003\end{array}$
vegetation

(C) Probability of detection of the Rufuous Whistler (effects shown graphically in Fig. 2e-g)

$\begin{array}{lcl}\text { Constant } & -8.31 & 3.75 \\ \text { Number of eucalypt patches } & 0.065 & 0.023 \\ \log \text { (mean area of patches) } & 0.496 & 0.237 \\ \text { Mean minimum distance to native } & 0.012 & 0.006\end{array}$

$\begin{array}{lll}\text { Mean minimum distance to native } & 0.012 \quad 0.006\end{array}$ vegetation

(D) Probability of detection of the Golden Whistler (effects shown graphically in Fig. 2h)

$\begin{array}{lll}\text { Constant } & 0.447 & 0.499 \\ \text { Year } 1997 & 0 & - \\ \text { Year } 1996 & -0.896 & 0.249 \\ \text { Mean minimum distance to native } & -0.007 & 0.004\end{array}$

Mean minimum distance to native $\quad-0.007 \quad 0.004$ vegetation

(E) Probability of detection of the Red Wattlebird (effects shown graphically in Fig. 2i-k)

$\begin{array}{lcl}\text { Constant } & -0.831 & 0.631 \\ \text { Year 1996 } & -1.321 & 0.241 \\ \text { Year 1997 } & 0 & - \\ \text { Road density } & 0.0003 & 0.0001 \\ \text { log(remnant area) } & 0.275 & 0.103 \\ \text { Mean minimum distance to native } & -0.009 & 0.004 \\ \quad \text { vegetation } & & \end{array}$

${ }^{\text {a }}$ Note that 2 years of field data (1996 and 1997) were used in data analyses and the between year effects were statistically significant for some species. The first level of this categorical variable (1997) was set to zero by default (see McCullagh and Nelder, 1989) in these cases.

landscape measures could be useful in guiding forest management decision-making (Hilty and Merenlender, 2000). It is stated in Commonwealth of Australia (1998) "that indicators provide measures of change in criteria which describe broad forest values that society wishes to maintain" (Commonwealth of Australia, 1998). In addition, "indicators can be a useful tool for assessing progress towards the achievement of sustainable forest management". The very general nature of these statements highlight the need to be much more specific about the definition and specification of target responses, as well as direct and indirect measures (e.g. landscape surrogates), before we can make progress in evaluating ecological indicators. There is also a requirement for criteria to determine whether an indicator is a valid or "a useful" tool. By borrowing ideas from the literature on the use of surrogate end points in clinical trails in medicine (Begg and Leung, 2000), we make suggestions for evaluating ecological indicators. Begg and Leung (2000) propose the following two analytical principles for evaluating the utility of surrogate endpoints:

- The best attainable inference relating to the defined units for study must arise from direct measures of the target response on these units.

- The validity of a surrogate measure should be judged by the probability that results based on the surrogates alone are 'concordant' with results that would be obtained if the direct measures were to be observed and analysed.

Thus, the general principle is that an analysis based on the direct measure represents the highest standard. The definition of 'concordance' is somewhat arbitrary, but one possibility is that forest management decisions arising from an analysis of the surrogate will be the same as those based on the direct measure. For example, the results of tests of significance on both the direct measure and the surrogate lead to the same conclusions. Begg and Leung (2000) provide rigorous mathematical and statistical arguments for their case. Clearly, it is possible that biological processes may affect the surrogate but not the direct measure, and so conclusions will be different, even though the correlation between the two measures is high. However, in general, for the principles outlined above, the smaller the association between the two measures, the greater the possibility for misleading inference. Thus, our two case studies of relationships between direct target responses and landscape surrogate measures are pertinent to a discussion on ecological indicators and forest fragmentation. 

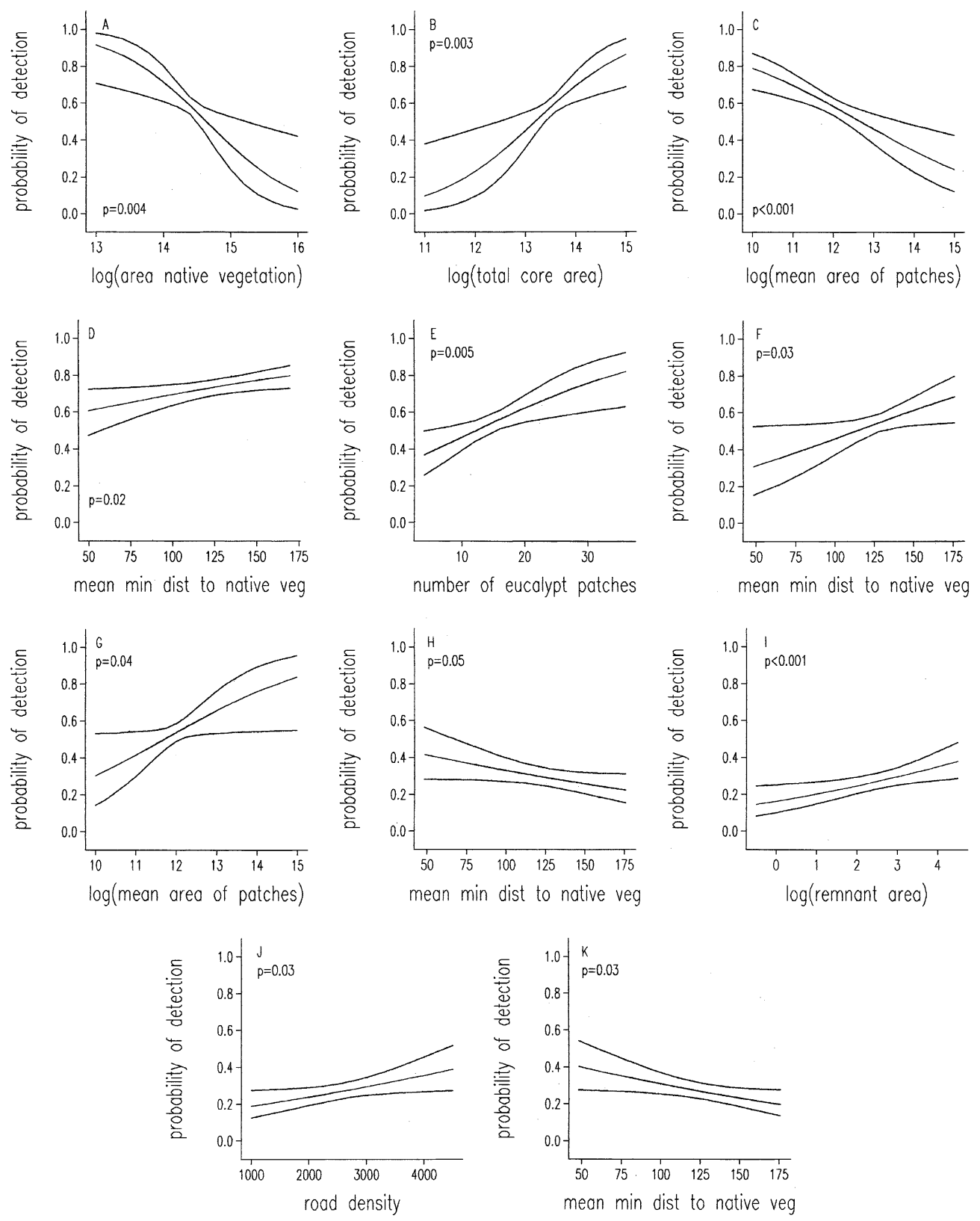

Fig. 2. Graphical representation of relationships between the detection frequencies of various species of birds and significant landscape variables: Crimson Rosella (A-C); Grey Fantail (D); Rufous Whistler (E-G); Red Wattlebird (H-K).

\subsection{Relationships between target responses and surrogate measures of landscape fragmentation}

No relationships with landscape surrogate measures were found in our first case study of arboreal marsupials in the Central Highlands of Victoria. Hence, for these data, there was no evidence of species responding to any of the constructed measures of human disturbance extracted from the National Wilderness Inventory. There are many possible 
Table 4

Parameter estimates and standard errors for relationships between the detection frequency of various species of birds in remnant patches of eucalypt forest at Tumut and a patchiness score derived from principal components analysis (see text) ${ }^{\mathrm{a}}$

\begin{tabular}{lcl}
\hline Variable & Estimate & \multicolumn{1}{c}{ S.E. } \\
\hline (A) Crimson Rosella (effects shown graphically in Fig. 3a) \\
Constant & 0.614 & 0.142 \\
Principal components score 1 & 0.250 & 0.049 \\
Year 1997 & 0 & - \\
Year 1996 & -0.562 & 0.197 \\
(B) Grey Fantail (effects shown graphically in Fig. 3b) & \\
Constant & 1.401 & 0.173 \\
Principal components score 1 & 0.108 & 0.051 \\
Year 1997 & 0 & - \\
Year 1996 & -0.680 & 0.227 \\
(C) Red Wattlebird (effects shown graphically in Fig. 3c) & \\
Constant & -0.443 & 0.147 \\
Principal components score 1 & -0.109 & 0.054 \\
Year 1996 & -1.256 & 0.246 \\
Year 1997 & 0 & - \\
\hline
\end{tabular}

${ }^{\text {a }}$ Note that 2 years of field data (1996 and 1997) were used in data analyses and the between year effects were statistically significant for some taxa. The first level of this categorical variable (1997) was set to zero by default (see McCullagh and Nelder, 1989) in these cases.

reasons for this result: (1) arboreal marsupials are not susceptible to the forms of human disturbance captured by the National Wilderness Inventory, (2) the surrogate measures of landscape fragmentation were insufficiently sensitive to changes in forest age and stand structure which occur with logging in montane ash forest and to which arboreal marsupials are known to respond (Lindenmayer and Franklin, 1997), (3) the spatial scale at which landscape surrogate measures were derived, or the accuracy and precision of the primary attribute data on which these measures were based, did not match the spatial scale at which animals perceive the environment (see Cale and Hobbs, 1994), or (4) the selected landscape measures were not good surrogates for making inferences about arboreal marsupials.

In the Tumut case study, different combinations of landscape surrogate measures were found to predict presence/abundance of different species (Tables 2 and 3 ). This result was not surprising. In models with the same significant explanatory variable, the sign for trends in the variable was often different (e.g. for the mean minimum distance to native vegetation for the Grey Fantail and the Golden Whistler, see Fig. 2). Hence, each species responded differently to the landscape mosaic at Tumut-a result consistent with other studies where the response of an array of taxa to fragmentation has been examined (e.g. Robinson et al., 1992; Gascon et al., 1999). In one case-that of the Eastern Yellow Robin-no significant relationships with any measure were found. This is consistent with earlier studies which showed that the Eastern Yellow Robin not only occurred in the eucalypt remnants but there also was a high probability of detection in the surrounding stands of Radiata Pine (Lindenmayer et al., 2001). Alternatively the measures selected in this study did not capture important aspects of landscape pattern for the species.

The Tumut case study produced several unexpected findings, such as the result for the total number of arboreal marsupials. The abundance of arboreal marsupials increased significantly with remnant area, but decreased with an increasing amount of native vegetation in the surrounding landscape.
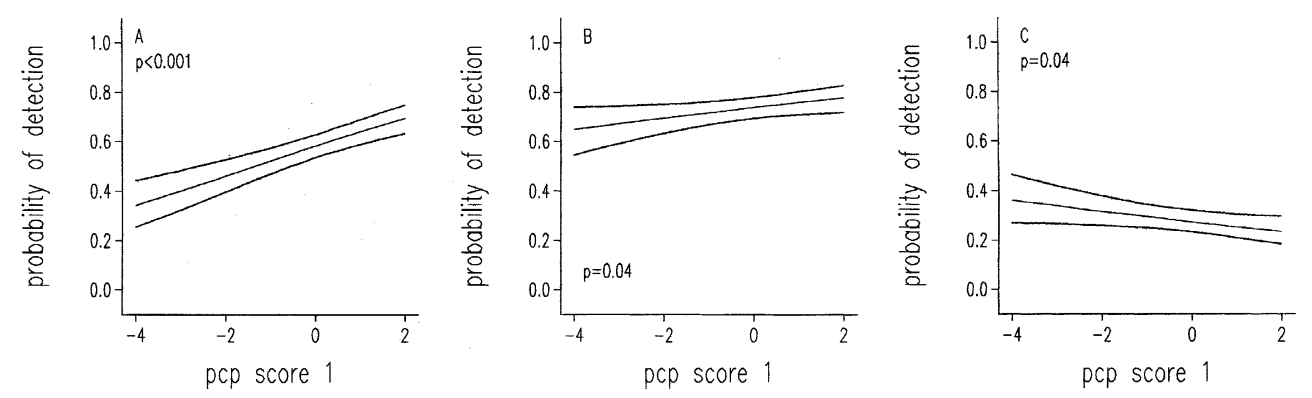

Fig. 3. Graphical representation of relationships between the detection frequencies of various species of birds and a patchiness score derived from principal components analysis: Crimson Rosella (A); Grey Fantail (B); Red Wattlebird (C). 
Thus, "isolated" remnants surrounded predominantly by Radiata Pine supported significantly more animals than did those of equivalent size but where the surrounding landscape included other areas of native vegetation. Hence, population dynamics within a remnant appears to be influenced by what is occurring outside it (in this case the surrounding Radiata Pine stands). We suspect that a "fence effect" (sensu Wolff et al., 1997) may be occurring in more isolated eucalypt remnants at Tumut. The unsuitability of the surrounding Radiata Pine plantation may make animals reluctant to disperse away from eucalypt remnants. This would increase population density relative to those remnants where other areas of eucalypt forest occurred in the surrounding landscape. This type of effect is not often reported, but has been seen in small mammals in fragmented landscapes in the northern Hemisphere (e.g. Krohne, 1997; Bayne and Hobson, 1998). Fence effects demand some plasticity in life history parameters such as increased population density, increased home range overlap, and reduced core home range size, as a consequence of remnant conditions. Notably, recent radio-tracking studies of the Greater Glider at Tumut have shown that these aspects of within-remnant population dynamics do change in response to remnant size and other constraints (Pope et al., unpublished data). The longterm impacts of phenomena like fence effects on population dynamics such as inbreeding depression are not known, but it is noteworthy that some of the eucalypt remnants targeted for study in the Tumut system have been surrounded by stands of Radiata Pine for almost 70 years. Further work that has only recently commenced to examine patterns of genetic variability among populations within eucalypt remnants (see Lindenmayer et al., 1999d) is required to determine if such types of fragmentation impacts have occurred at Tumut.

Most studies of wildlife in Australian softwood landscapes have focussed on which species are excluded from such stands of Radiata Pine and how faunal assemblages contrast with those typical of eucalypt forests (e.g. Friend, 1980; Smith, 1982). Other investigations have examined the taxa which persist in remnant eucalypt patches embedded within the plantation estate (Recher et al., 1987; Lindenmayer et al., 1999b,c). To the best of our knowledge, our study is the first in Australia to examine the relationship between faunal responses in plantation landscapes and landscape measures, which may act as surrogates for the direct measures. This project has shown that many species respond not only to the total area of eucalypt cover, but also to how that cover is spatially arranged. Some taxa were more likely to be recorded where eucalypt cover was consolidated (e.g. Red Wattlebird), whereas the opposite effect was identified for other species (i.e. eucalypt cover was dispersed, e.g. Crimson Rosella) (Fig. 3). Similarly, the Common Ringtail Possum was more likely to occur in a patchy (rather than consolidated) distribution of eucalypt remnants. This effect may be due to positive responses to edge conditions. The eucalypt-pine boundary may provide additional resources for some species. For example, the Common Ringtail Possum can use eucalypt forests and neighbouring stands for both food and shelter (Friend, 1980). A combination of forest types having shared boundaries may provide more resources than either Radiata Pine stands or eucalypt forest alone. These positive edge effects may explain the results of an earlier study (Lindenmayer et al., 1999b) in which there was a significantly $(P=0.005)$ higher abundance of the Common Ringtail Possum in eucalypt remnants (surrounded by Radiata Pine) than in large continuous stands of eucalypt forest.

The species response of animals to the patchiness score derived by principal co-ordinates analysis of landscape measures in the Tumut study area does not appear to be associated with home range or territory size. For example, the Red Wattlebird and the Crimson Rosella are both relatively large and mobile species, yet they showed the opposite response to our measure of patchiness. Similarly, the Grey Fantail, which is a small species with a relatively small territory size, showed a response similar to the much larger and more mobile Crimson Rosella. It is possible the interspecific differences in response are more strongly related to a species' ability to use the Radiata Pine matrix surrounding the eucalypt remnants than to territory size. The Grey Fantail, Crimson Rosella and Rufous Whistler are species that are commonly recorded in stands of Radiata Pine as well as eucalypt remnants (Lindenmayer et al., 2001) and the detection rate for these taxa increased when eucalypt cover was dispersed. The Red Wattlebird is less commonly recorded in the Radiata Pine matrix and this may 
explain why it was significantly more likely to be detected when eucalypt cover is consolidated.

\subsection{Landscape surrogate measures as ecological indicators}

In our first case study, there was no evidence to support an assertion that landscape surrogates are informative in making inferences about selected target responses in 3 ha sites in montane ash forests. The lack of correlation between the direct measures (i.e. the target responses) and the landscape surrogates (the values from the National Wilderness Inventory) mean the surrogate measures would not be valid or useful tools (or "ecological indicators") to guide decisionmaking for arboreal marsupials in the Central Highlands of Victoria. In the case of the Tumut study, our investigation of relationships between landscape surrogate measures and target responses did not assist in identifying particular surrogate measures for the full range of biota considered. In some cases there was strong evidence of relationships between direct measures and some of the landscape surrogates, but for other target responses there was no evidence for relationships. As each species responds differently to the same spatial scale of landscape change and human disturbance (e.g. Davies and Margules, 1997; Villard et al., 1999), we should not expect any single landscape surrogate measure (or even an extensive suite of surrogate measures) to adequately reflect forest fragmentation for biota per se. Even remnant area, a landscape surrogate measure considered to be critical in many aspects of landscape ecology (Forman, 1995), and metapopulation biology (Hanski, 1999), was not a useful predictor for all the taxa examined at Tumut. Other studies have shown that factors other than remnant area can be the most important ones in some landscapes (e.g. Metzger, 1997; Gascon and Lovejoy, 1998).

Inter-specific variation in response to landscape change means that the use of landscape surrogate measures should be qualified by an explicit statement of the question they will be used to address and the biology and ecology of the target response organisms being examined, particularly the spatial scale/s relevant to their existence (Cale and Hobbs, 1994). If landscape surrogate measures are used in this way, they can yield valuable new insights about target responses to landscape cover, as occurred for vertebrates at Tumut.

Another important aspect of our two case studies was the high collinearity among derived landscape surrogate measures. Other authors have reported similar findings (e.g. Riitters et al., 1995; Hargis et al., 1998). It is therefore imperative that in the search for valid surrogates, only variables which provide independent information be chosen-simply re-expressing the same raw data in different ways will not improve predictions.

Several authors have reviewed landscape measures and stressed the need to be cognisant of the scale at which they are applied and matching this to the scale at which organisms perceive their environment (e.g. Cale and Hobbs, 1994). However, this can be influenced by the ability of species to use the landscape matrix surrounding patches, as appeared to occur among species of birds at Tumut. Surrogate landscape variables were applied at one scale in our studies in Victoria (data surfaces at a resolution of $500 \mathrm{~m}$ ) and at another in Tumut. Significant relationships were found at Tumut at the scale of a $2000 \mathrm{~m}$ polygon around the centroid of eucalypt remnants. However, we found in earlier studies that variables at other scales have an important influence on the distribution and abundance of mammals and birds at Tumut. In earlier studies, structural and floristic attributes of individuals trees and stands (measured on plots along the $600 \mathrm{~m}$ long field sampling transect) were found to be related to habitat suitability for arboreal marsupials and forest birds (Lindenmayer et al., 1999b,d, 2001). Landscape measures do not capture these important tree and plot-level features. It is important, therefore, to recognise that while landscape measures may reflect important relationships for some species at a given scale, factors at other scales also will shape patterns of distribution and abundance. For example, arboreal marsupials in the Central Highlands of Victoria respond strongly to the characteristics of trees with hollows which they use as nest sites-attributes of individual trees such as diameter and the prevalence of cavities significantly influence whether they are occupied by particular species (Lindenmayer et al., 1991b).

The length of isolation of habitat remnants can be an important predictor of species occurrence in some landscapes (Bennett, 1990). Clearly this effect cannot 
be quantified by cross-sectional data taken at one time point. In other cases, fragmentation effects can appear and then disappear again depending on the regeneration dynamics of the landscape surrounding a given patch (such as logged and regeneration stands in wood production forests) (Fahrig, 1992).

Some landscape measures like the ones we extracted from the National Wilderness Inventory (see Table 1A) may be useful for describing various aspects of landscape "naturalness" and/or landscape pattern (sensu Forman, 1995) from a human perspective. This can be valuable where the aim is to monitor the extent and rate of change of that pattern over time. However, these measures and the changes in them may or may not reflect the response of given species to disturbance, as in the case of the Eastern Yellow Robin at Tumut.

We hope that the ideas presented in this paper will serve as a catalyst to others to undertake work which may lead to the development of a framework for evaluating ecological indicators. We believe that little progress can be made in this area until such a framework is established. In order to increase the chance of success, contributions will be required from scientists in many disciplines, in particular statistical science and ecology.

\section{Acknowledgements}

Forest and Wood Products Research and Development Corporation commissioned this study. We most gratefully acknowledge the support of that organisation. This work has been conducted in collaboration with Dr. C. McAlpine, and Dr. T. Eyre. Field studies at Tumut are supported by major grants from Land and Water Research and Development Corporation, Forest and Wood Products Research and Development Corporation, Rural Industries Research and Development Corporation, and the NSW Department of Land and Water Conservation. Other supporting bodies for various projects in the Nannangroe and Tumut regions were NSW National Parks and Wildlife Service, State Forests of NSW, Environment Australia, Brookfield Zoo, Chicago, USA, The Pratt Foundation (Visy Industries), and CSR Ltd. We are also grateful to Jim Atkinson and Di Stockbridge for their private donation. Mr. M. Pope, Mr. C. MacGregor and the
Canberra Ornithologists Group assisted with the collection of data on birds and arboreal marsupials at Tumut. Ongoing field studies in the Central Highlands of Victoria are supported by Parks Victoria the Earth Water Institute, the Victorian Department of Natural Resources and Environment, and Environment Australia and the Myes foundation. Environment Australia also made available wilderness data from the National Wilderness Inventory for the Central Highlands of Victoria. Comments by a wide range of colleagues, but especially Mr. A. Gilmore, Mr. R. Smith, Dr. C. McAlpine and Dr. K. Viggers considerably improved earlier versions of the manuscript.

\section{References}

Arborvitae, 1995. IUCN/WWF For. Conserv. Newslett. 1 (September), 5.

Bayne, E.M., Hobson, K.A., 1998. The effects of habitat fragmentation by forestry and agriculture on the abundance of small mammals in the southern boreal mixedwood forest. Can. J. Zool. 76, 62-69.

Begg, C.B., Leung, D.H.Y., 2000. On the use of surrogate end points in randomized trials. J. R. Statist. Soc. A. 163, 15-28.

Bennett, A.F., 1990. Land use, forest fragmentation and the mammalian fauna at Naringal southwestern Victoria. Aust. Wildl. Res. 17, 325-347.

Cale, P.G., Hobbs, R.J., 1994. Landscape heterogeneity indices: problems of scale and applicability, with particular reference to animal habitat description. Pacific Conserv. Biol. 1, 183-193.

Canadian Forest Service, 2000. The Montreal Process: Year 2000 Progress Report. Canadian Forest Service, Ottawa, Canada.

Commonwealth of Australia, 1998. A framework of regional (subnational) level criteria and indicators of sustainable forest management in Australia. Commonwealth of Australia, Canberra, Australia.

Commonwealth of Australia and Department of Natural Resources and Environment, 1997. Comprehensive Regional Assessment-Biodiversity. Central Highlands of Victoria. The Commonwealth of Australia and Department of Natural Resources and Environment, Canberra, Australia.

Davies, K.F., Margules, C.R., 1997. Effects of habitat fragmentation on carabid beetles: experimental evidence. J. Anim. Ecol. 67, 460-471.

Digby, P.G., Kempton, R.A., 1987. Multivariate Analysis of Ecological Communities. Chapman \& Hall, London.

Enoksson, B., Angelstam, P., Larsson, K., 1995. Deciduous forest and resident birds: the problem of fragmentation within a coniferous forest landscape. Landsc. Ecol. 10, 267-275.

Fahrig, L., 1992. Relative importance of spatial and temporal scales in a patchy environment. Theor. Popul. Biol. 41, 300-314.

Forman, R.T.T., 1995. Land mosaics. In: The Ecology of Landscapes and Regions. Cambridge University Press, New York. 
Friend, G.R., 1980. Mammal populations in exotic pine plantations and indigeneous forests in Gippsland, Victoria. Aust. For. 45, $3-18$.

Gascon, C., Lovejoy, T.E., 1998. Ecological impacts of forest fragmentation in central Amazonia. Zoology 101, 273-280.

Gascon, C., Lovejoy, T., Bieeregaard, R.O., Malcolm, J.R., Stouffer, P.C., Vasconcelos, H.L., Laurance, W.F., Zimmerman, B., Tocher, M., Borges, S., 1999. Matrix habitat and species richness in tropical forest remnants. Biol. Conserv. 91, 223-229.

Gill, F.B., 1995. Ornithology, 2nd Edition. Freeman, New York.

Groombridge, B. (Ed.), 1992. IUCN Red List of Threatened Animals. Gland, Switzerland.

Haines-Young, R., Chopping, M., 1996. Quantifying landscape structure: a review of landscape indices and their application to forested environments. Progr. Phys. Geogr. 20, 418-445.

Hanski, I., 1999. Metapopulation Ecology. Oxford University Press, Oxford.

Hargis, C.D., Bissonette, J.A., David, J.L., 1998. The behaviour of landscape metrics commonly used in the study of habitat fragmentation. Landsc. Ecol. 13, 167-186.

Hilty, J., Merenlender, A., 2000. Faunal indicator taxa selection for monitoring ecosystem health. Biol. Conserv. 92, 185-197.

Krohne, D.T., 1997. Dynamics of metapopulations of small mammals. J. Mammal. 78, 1014-1026.

Lamberson, R.H., Noon, B.R., Voss, C., McKelvey, R., 1994. Reserve design for territorial species: the effects of patch size and spacing on the viability of the Northern Spotted Owl. Conserv. Biol. 8, 185-195.

Laurance, W.F., Bierregaard, R.O., 1997. Tropical forest remnants. In: Ecology, Management and Conservation of Fragmented Communities. The University of Chicago Press, Chicago.

Lesslie, R., Maslen, M., 1995. National Wilderness Inventory Handbook, 2nd Edition. Australian Heritage Commission, Australian Government Publishing Service, Canberra, Australia.

Lindenmayer, D.B., Franklin, J.F., 1997. Forest structure and sustainable temperate forestry: a case study from Australia. Conserv. Biol. 11, 1053-1068.

Lindenmayer, D.B., Cunningham, R.B., Tanton, M.T., Nix, H.A., Smith, A.P., 1991a. The conservation of arboreal marsupials in the montane ash forests of the Central Highlands of Victoria, southeast Australia. III. The habitat requirements of Leadbeater's Possum, Gymnobelideus leadbeateri McCoy and models of the diversity and abundance of arboreal marsupials. Biol. Conserv. 56, 295-315.

Lindenmayer, D.B., Cunningham, R.B., Tanton, M.T., Smith, A.P., Nix, H.A., 1991b. Characteristics of hollow-bearing trees occupied by arboreal marsupials in the montane ash forests of the Central Highlands of Victoria, southeastern Australia. For. Ecol. Manage. 40, 289-308.

Lindenmayer, D.B., Cunningham, R.B., Donnelly, C.F., 1994. The conservation of arboreal marsupials in the montane ash forests of the Central Highlands of Victoria, southeast Australia. VI. Tests of the performance of models of nest tree and habitat requirements of arboreal marsupials. Biol. Conserv. 70, 143-147.
Lindenmayer, D.B., Cunningham, R.B., McCarthy, M., 1999a. The conservation of arboreal marsupials in the montane ash forests of the Central Highlands of Victoria, southeastern Australia. VIII. Landscape analysis of the occurrence of arboreal marsupials in the montane ash forests. Biol. Conserv. 89, 83-92.

Lindenmayer, D.B., Cunningham, R.B., Pope, M., Donnelly, C.F., 1999b. The Tumut fragmentation experiment in southeastern Australia: the effects of landscape context and fragmentation on arboreal marsupials. Ecol. Appl. 9, 594-611.

Lindenmayer, D.B., Cunningham, R.B., Pope, M.L., Donnelly, C.F., 1999c. A field-based experiment to examine the response of mammals to landscape context and habitat fragmentation. Biol. Conserv. 88, 387-403.

Lindenmayer, D.B., Lacy, R.C., Tyndale-Biscoe, H., Taylor, A., Viggers, K., Pope, M.L., 1999d. Integrating demographic and genetic studies of the Greater Glider (Petauroides volans) at Tumut, southeastern Australia: setting hypotheses for future testing. Pacific Conserv. Biol. 5, 2-8.

Lindenmayer, D.B., Cunningham, R.B., Donnelly, C.F., Nix, H.A., 2001. The distribution of birds in a fragmented forest landscape. Ecology, in press.

Majer, J.D., Recher, H.F., Postle, A.C., 1994. Comparison of arthropod species richness in eastern and western Australian canopies: a contribution to the species number debate. Memoirs of the Queensland Museum 36, 121-131.

McCullagh, P., Nelder, J.A., 1989. Generalised Linear Models, 2nd Edition. Chapman \& Hall, New York.

Metzger, J.P., 1997. Relationships between landscape structure and tree species diversity in tropical forests of southeast Brazil. Landsc. Urban Plann. 37, 29-35.

Noss, R.F., 1999. Assessing and monitoring forest biodiversity: a suggested framework for indicators. For. Ecol. Manage. 115, 135-146.

Økland, B., 1996. Unlogged forests: important sites for preserving the diversity of mycetophilids (Diptera: Sciaroidea). Biol. Conserv. 76, 297-310.

Recher, H.F., Shields, J., Kavanagh, R., Webb, G., 1987. Retaining remnant mature forest for nature conservation at Eden, New South Wales: a review of theory and practice. In: Saunders, D.A., Arnold, G.W., Burbidge, A.A., Hopkins, A.J. (Eds.), Nature Conservation: The Role of Remnants of Vegetation. Surrey Beatty and Sons, Chipping Norton, Australia, pp. 177-194.

Riitters, K.H., O’Neill, R.V., Hunsaker, C.T., Wickham, J.D., Yankee, D.H., Timmins, S.P., Jones, K.B., Jackson, B.L., 1995. A factor analysis of landscape pattern and structure metrics. Landsc. Ecol. 10, 23-39.

Robinson, G.R., Holt, R.D., Gaines, M.S., Hamburg, S.P., Johnson, M.L., Fitch, H.S., Martinko, E.A., 1992. Diverse and contrasting effects of habitat fragmentation. Science 257, 524-526.

Smith, J.M., 1982. Ecological comparisons between pine plantations and native forests, Clouds Creek, New South Wales. In: Research Series in Applied Geography. University of New England, Armidale, Australia.

Temple, S.A., 1986. The problem of avian extinctions. Curr. Ornithol. 3, 453-485.

Torsvik, V., Goksoyr, J., Daae, F., 1990. High diversity in DNA of soil bacteria. Appl. Environ. Microbiol. 56, 782-787. 
Villard, M.A., Trzcinski, M.K., Merriam, G., 1999. Fragmentation effects on forest birds: relative influence of woodland cover and configuration on landscape occupancy. Conserv. Biol. 13, 774-783.

Virkkala, R., Rajasarrkka, A., Vaisanen, R.A., Vickholm, M., Virolainen, E., 1994. The significance of protected areas for the land birds of southern Finland. Conserv. Biol. 8, 532-544.
Wegner, J., 1994. Ecological landscape variables for monitoring and management of forest biodiversity in Canada. Report to Canadian Ministry of Natural Resources by GM Group, Ecological Land Management, Manotick, Canada.

Wolff, J.O., Schauber, E.M., Edge, W.D., 1997. Effects of habitat loss and fragmentation in the behavior and demography of Gray-tailed Voles. Conserv. Biol. 11, 945-956. 